\title{
Performance of Chinese medical postgraduate students in literature searching: a two-center survey and analysis
}

\author{
Zhi Mao"^${ }^{1 \#}$, Ting Wu ${ }^{2 \#}$, Jiabing Zhang ${ }^{3}$, Dan Feng ${ }^{4}$, Jinsong Chen ${ }^{5}$, Chao Liu ${ }^{6}$, Shuang $\mathbf{Q i}^{1}$, Qinglin $\mathrm{Li}^{1}$, \\ Hongjun Kang', Feihu Zhou, ${ }^{1,6}$
}

${ }^{1}$ Department of Critical Care Medicine, the first Medical Centre, Chinese PLA General Hospital, Beijing, China; ${ }^{2}$ Department of Pain Treatment, Xiangyang No. 1 People's Hospital, Hubei University of Medicine, Xiangyang, China; ${ }^{3}$ Graduate College, Chinese PLA General Hospital, Beijing, China; ${ }^{4}$ Institute of Hospital Management of Medical Innovation Research Department, Chinese PLA General Hospital, Beijing, China; ${ }^{5}$ Department of Gerontology, Zhangzhou Zhengxing Geriatric Hospital, Zhangzhou, China; ${ }^{6}$ National Clinical Research Center for Kidney Diseases, Chinese PLA General Hospital, Beijing, China

Contributions: (I) Conception and design: Z Mao, T Wu, F Zhou; (II) Administrative support: J Zhang, C Liu, D Feng, F Zhou; (III) Provision of study materials or patients: J Zhang, C Liu, S Qi, D Feng, Q Li, H Kang; (IV) Collection and assembly of data: T Wu, J Zhang, J Chen, Z Mao,; (V) Data analysis and interpretation: T Wu, J Chen, Z Mao, F Zhou; (VI) Manuscript writing: All authors; (VII) Final approval of manuscript: All authors.

\#These authors contributed equally to this work and are co-first authors.

Correspondence to: Feihu Zhou. Department of Critical Care Medicine, Chinese People's Liberation Army General Hospital, Beijing, China. Email: feihuzhou301@126.com.

Background: To explore the performance status of Chinese postgraduate medical students in literature searching.

Methods: A self-designed online questionnaire was used to assess the literature search performance of postgraduate students (PGSs) from the classes of 2016, 2017, 2018, and 2019 from two medical colleges. The items of the questionnaire mainly included: the demographic characteristics of the PGSs, methods of literature review, literature reading habits, and use of literature. We also designed a self-assessed score that ranged from the lowest 1 point to the highest 5 points.

Results: A total of 902 PGSs (482 male, average age: $29.4 \pm 5.8$ years old, working time range: 0-10 years, average $3.7 \pm 2.4$ years) completed the questionnaire. Most PGSs investigated literature only at the work tasks $(632,70.1 \%)$ and writing papers $(571,63.3 \%)$ stages. Of the PGSs, 542 (60.1\%) PGSs searched literature frequency ( $\geq 1$ paper/week), and 114 (12.6\%) did not perform advanced searches, and some had no knowledge of advanced search techniques at all. Most PGSs had not read more than 100 Chinese articles or English articles before. Most PGSs were used to read articles from the most authoritative journals (665, $73.7 \%)$ or high impact factor (IF) $(540,59.9 \%)$. PGSs $(845,93.7 \%)$ only read the full text of articles they deemed important. Of the PGSs, 441 (48.9\%) did not use literature management tools. For self-assessed score of literature searching and reading skills, the mean was 2.1 (standard deviation, 0.8). Reading literature efficiently $(710,78.7 \%)$ and tracking recent literatures $(615,68.2 \%)$ were the two needed literature skills reported.

Conclusions: Chinese medical PGSs still have room for improvement in relation to literature investigation. Intensive training in literature searching should be given to improve their performance.

Keywords: Postgraduate students (PGSs); literature search; strategy

Submitted Aug 20, 2020. Accepted for publication Oct 27, 2020.

doi: 10.21037/atm-20-6932

View this article at: http://dx.doi.org/10.21037/atm-20-6932

^ ORCID: 0000-0002-1170-6637. 


\section{Introduction}

Literature searching skills are crucial for researchers and enable related articles or material, including the latest scientific findings, to be found $(1,2)$. In the knowledge era, practitioners should keep up to date with scientific and technological progress, especially in the area of medicine $(3,4)$. However, with the widespread use of the Internet, it is easy to get lost in an ocean of specific information (5); therefore, efficiently obtaining the information we actually need can prove extremely difficult. PubMed and Google scholar may be the most popular professional databases used by investigators worldwide to search for literature. In China, Chinese-language medical literature databases, including China National Knowledge Infrastructure (CNKI), Wanfang database, and Baidu scholar, are also important resources. Some studies reveal gaps in the writer's literature search performance. In China, considerable emphasis is put on literature reading and searching during the course of study (6). However, in practice, we have found that there are some practitioners who cannot or do not use literature searches professionally, which hampered their career development and had negative influences on the quality of medical research. Therefore, the current study aimed to better understand the actual situation and underlying reasons for this phenomenon by designing a questionnaire for postgraduate students (PGSs) from the classes of 2016, 2017, 2018, and 2019 from two medical colleges.

We present the following article in accordance with the SURGE reporting checklist (available at http://dx.doi. org/10.21037/atm-20-6932).

\section{Methods}

\section{Study population}

PGSs from the classes of 2016, 2017, 2018, and 2019 were enrolled. These PGSs were educated at two postgraduate medical colleges: $732(81.2 \%)$ came from Medical Postgraduate College of People's Liberation Army General Hospital (PGH, also known as Medical University of People's Liberation Army, Beijing, China) and 170 (18.8\%) came from Postgraduate College of Medical College of Nankai University (MC of NKU, Tianjin, China). Signed informed consent was obtained from each participant. This survey was about student habits not related to human health and ethical approval was not required. The study was conducted in accordance with the Declaration of Helsinki (as revised in 2013).

\section{Questionnaire and score}

To gain a deeper insight into the performance of Chinese medical PGSs in literature searching, we designed online version questionnaire (www.wjx.cn). This questionnaire mainly focused on: (I) literature search methods, including search tools, the use of advanced search, and the frequency of searching activities; (II) habits of literature reading, including full-text, intensive, or extensive reading, and the number of articles read per month; and (III) use of literature, including purpose of literature searching and reading, reference management tools, and citation of published articles. We also designed a self-assessed score for researching and reading skills. One point is the lowest, and 5 point is the highest. No incentives were provided.

\section{Statistical analysis}

The results data of this cross-sectional survey were recorded in a data sheet in SPSS (version 17.0 for Windows, SPSS, Inc., Chicago, IL, USA). We calculated the response rate. Nonresponse was calculated as missing data. Normally distributed and equally dispersed variables were compared using an unpaired two-sided Student's $t$-test. Categorical variables were expressed as numbers and percentages (\%). Wilcoxon rank sum test was used to analyze factors grouped by year of class. Self-assessed scores were expressed as the mean \pm standard deviation $(\bar{x} \pm \mathrm{SD})$, and one way ANOVA were used. A $\mathrm{P}$ value of $<0.05$ was considered statistically significant. All statistical analyses were performed with SPSS.

\section{Results}

\section{PGSs}

Among the 1,166 PGSs enrolled, 902 respondents reported questionnaires with response rate as $77.4 \%$. Two hundred fifty five $(28.3 \%)$ were studying for a doctor's degree and 647 (71.7\%) were master's students. Males accounted for a majority of the participants (482, 53.4\%). The students had an average age of $29.4 \pm 5.8$ years, and most $(86.6 \%, 781)$ were under the age of 35 years. Time of career ranged from $0-10$ year, with an average of $3.7 \pm 2.4$ years. Only $119(13.2 \%)$ PGSs had published English articles before admission. Table 1 lists the baseline characteristics of the PGSs. 
Table 1 Baseline characteristics and literature search performance scores of medical postgraduate students from two colleges in China

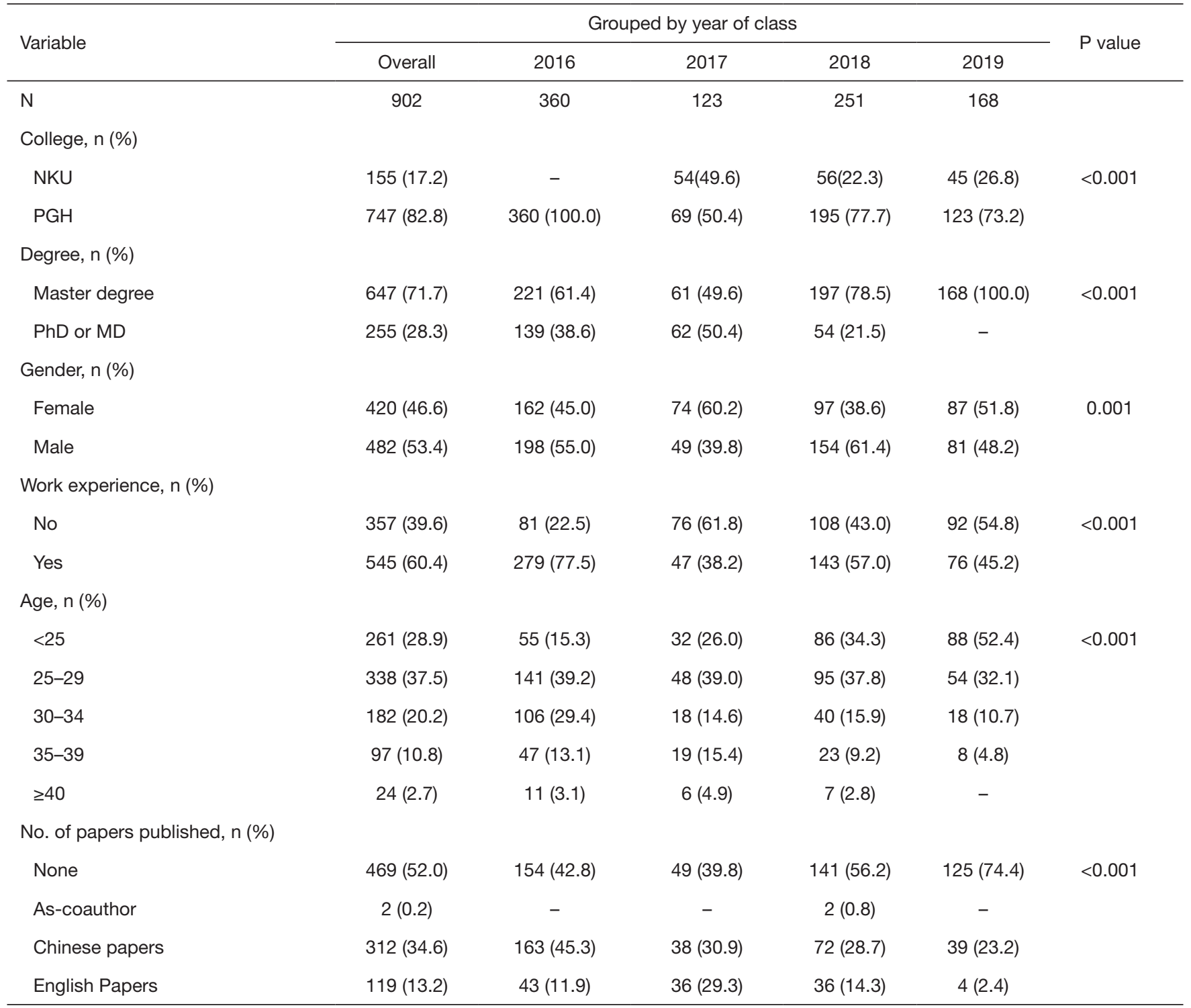

PGH, People's Liberation Army General Hospital; MC of NKU, Medical College of Nankai University ; MD, medical doctor degree; PhD, Doctor of Philosophy Degree.

\section{Literature search methods}

PubMed was the main tool used by the PGSs to search for English articles, and CNKI (China National Knowledge Infrastructure) was the main tool used for Chinese-language searches. 542 (60.1\%) PGSs searched literature frequency ( $\geq 1$ paper/week). Of the PGSs, 114 (12.6 \%) did not carry out an advanced search and some of them even had no knowledge of how to perform one. A majority of the PGSs had not read more than 100 Chinese or English articles before (Table 2). Further analysis revealed that some of the participants read the full texts of articles, but some did not because they only read the abstract. Work tasks (632, $70.1 \%)$, writing papers $(571,63.3 \%)$, writing protocols (41.3, 45.8\%), clinical case presentations $(350,38.8 \%)$ and doing experiments $(312,34.6 \%)$ were main literature prepared scenarios (Figure 1). In terms of the sources of articles, the PGSs were used to read articles from the most authoritative journals $(665,73.7 \%)$ or high impact factor (IF) $(540,59.9 \%)$ (Figure 2). 
Table 2 The literature searching habits of Chinese medical postgraduate students

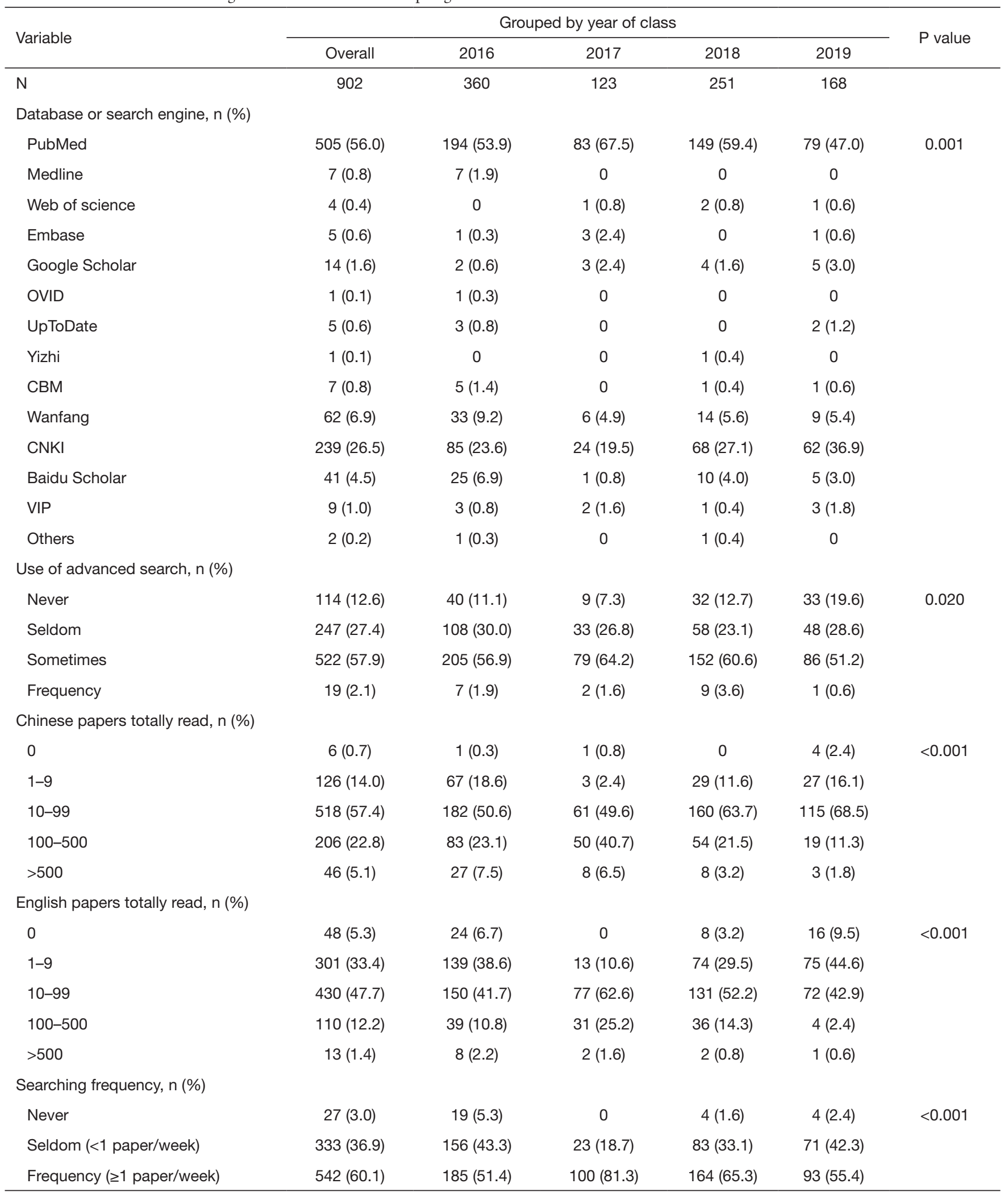

CBM, Chinese Biomedical Literature Database; CNKI, China National Knowledge Infrastructure; OVID, Ovid technologies; VIP, Weipu. 


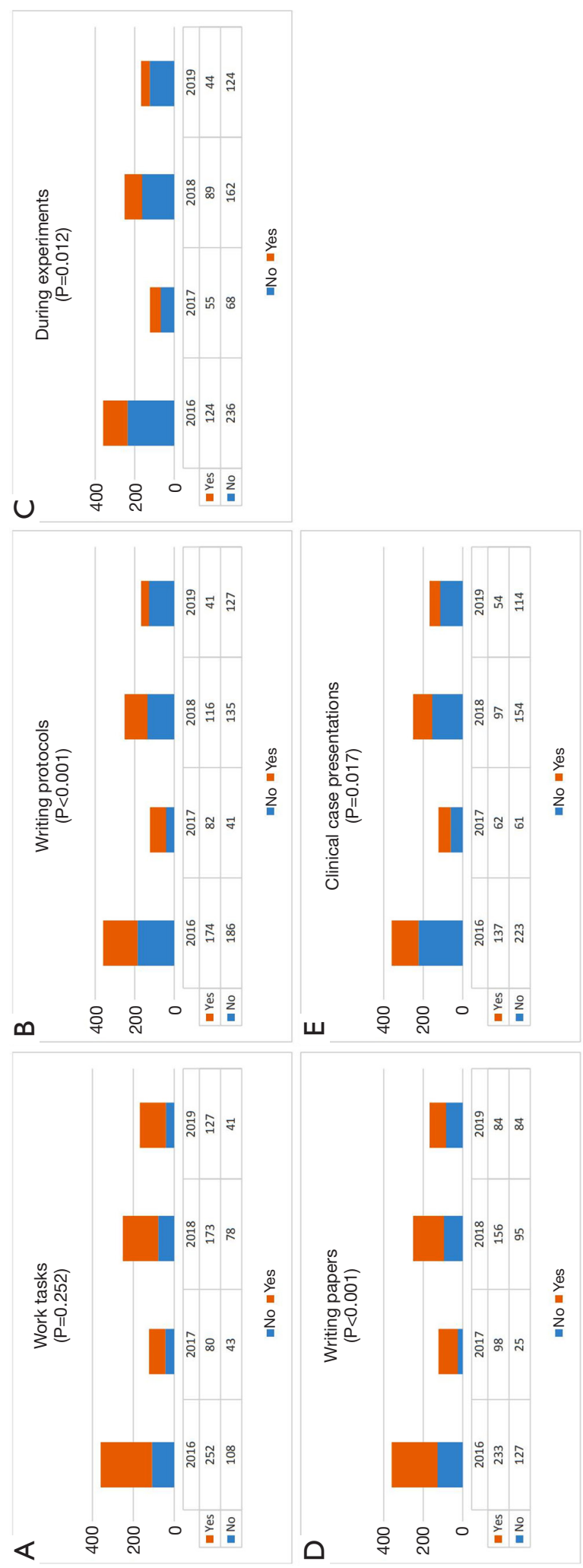

\section{Literature reading habits}

In this survey, most PGSs $(845,93.7 \%)$ only read the full text of articles they deemed important. Only 42 (4.7\%) PGSs were used to read full-text. For the purpose of reading papers, most reason was to improve the research ability (804, $89.1 \%)$ followed by performing tasks $(123,13.6 \%)$ and preparing papers or fundings $(235,26.1 \%)$. With regards to factors hindering searching and reading, limited searching skills and poor English were two top factors (both 641, $71.1 \%)$, and these two factors were significantly difference from 2016 to 2019 ( $\mathrm{P}=0.011, \mathrm{P}<0.001$, respectively) (Table 3). The top reading sequence for sections of literature was reading in natural order (Table S1).

\section{Use of reference management software and the needed literature skills}

A total of 441 (48.9\%) PGSs chose to not use literature management tools; some of these PGSs were unaware such tools existed, while others were unsure of how to use them. Of the PGSs who chose to use reference management tools, 379 (42.0\%) used Endnote, 49 (5.4\%) used Medical Reference King, and 26 (2.9\%) used NoteExpress. For self-assessed score for literature searching and reading skills, the mean was 2.1 (SD, 0.8). From 2016 to 2019, the difference of the selfassessed score was significantly $(\mathrm{P}<0.001)$ (Figure 3$)$. The needed literature skills were reading literature efficiently $(710$, $78.7 \%$ ) and tracking recent literatures (615, 68.2\%) (Table 4).

\section{Discussion}

To our best knowledge, this study has reported the literature search performance of medical PGSs from two distinguished medical colleges for the first time. We found that not all PGSs had sufficient literature searching skills, which negatively influenced their research. Chinese medical practitioners have the choice of English literature or Chinese literature searches. PubMed is often the resource used to search English-language articles, and count PGH and NKU among its subscribers. PGH and NKU also have subscribed other databases, including Medline, Embase, Web of Science, Lippincott, Williams \& Wilkins (LWW) database, and the Cochrane Library (7). Full text articles can be downloaded through links provided by PubMed or directly from the other databases. All of these databases provide a fuzzy search in the homepage search box as well as an advanced search tool. For Chinese-language medical 
A
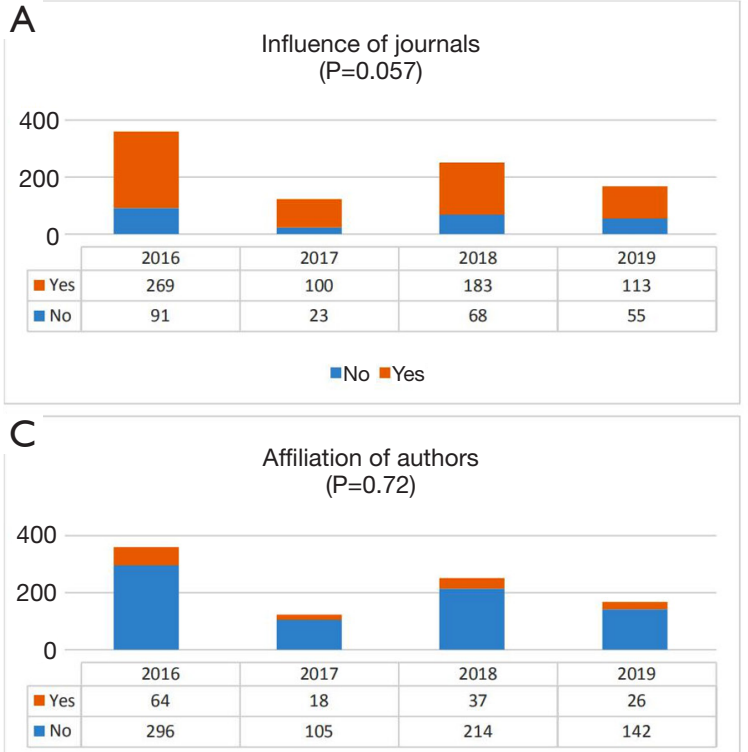

$\square$ No $=$ Yes

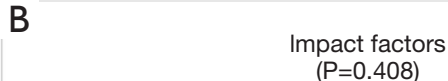

$(P=0.408)$

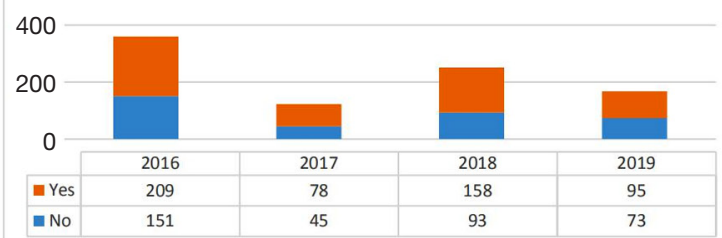

$\square$ No $\square$ Yes

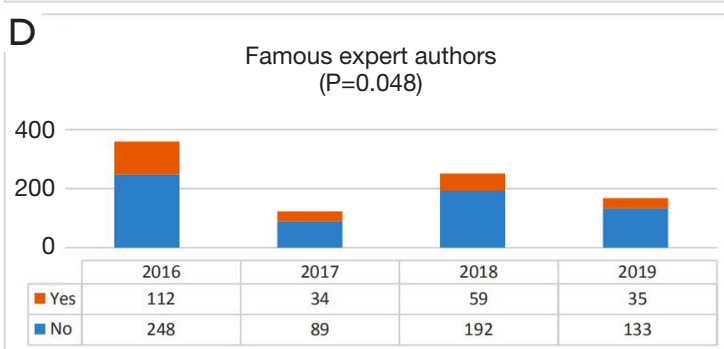

$\square$ No $\square$ Yes

Figure 2 According to what to choose a paper to read? (A) Influence of journals; (B) impact factors; (C) affiliation of authors; (D) famous expert authors.

literature, CNKI and Wanfang database are popular resources. These databases also provide fuzzy search and advanced search options and links for full-text downloads. Advanced searching skills are extremely useful (8). In general, PGSs from the two colleges in this study can carry out medical literature searches whenever and for whatever they want. However, the performance of the PGSs in the current study failed to meet our initial expectations. Some doctorate students had more experience in literature searching from their previous research work and had even published English articles previously. Younger PGSs were more familiar with the network and computers technology and had superior English language skills. The PGSs of classes 2018 and 2019 received better literature searching training and had more convenient network facilities, but they self-assessed scores were not better.

As for searching tools, PubMed and other English literature databases could meet PGSs' basic needs. For Chinese literature, CNKI does not include articles from some high-level journals, such as Chinese Medical fournal (Chinese version), Cbinese fournal of Internal Medicine, and Chinese Fournal of Cardiology. However, these journals can be found on Wanfang database. On the other hand, unlike CNKI, Wanfang database does not include articles from Chinese journals of general practice. Likewise, some
English articles, especially full texts, cannot be found through PubMed alone. Furthermore, some research areas are reported on more or less frequently in English journals compared to Chinese journals. Besides Chinese traditional medicine, recent progress in areas such as integrated elderly care (a Chinese-specific model for taking care of the elderly), reform or administration of public hospitals, or orthopedics, especially surgery of the upper cervical spine, has been reported frequently in Chinese medical journals. Therefore, students should cross-search multiple databases to avoid omitting articles of relevance (9). Unfortunately, the present study revealed that some PGSs had no knowledge of or chose not to use cross-search techniques. Cross-searching is an important skill that enables investigators to dig deeply through literature (10) and should be a focus of future training.

In China, PGSs spend at least 3 years studying for their master's or doctor's degrees, and during this time, they should constantly review the latest literature associated with their field (11). However, not all of the PGSs in our study kept up to date with specific scientific progress. Some PGSs only searched literature during the preparation stage of their research work, with some performing a further literature search at the paper-writing stage. Only a few participants carried out literature searches throughout the 
Table 3 Literature reading habits of Chinese medical postgraduate students

\begin{tabular}{|c|c|c|c|c|c|c|}
\hline Variable & \multicolumn{5}{|c|}{ Grouped by year of class } & $P$ value \\
\hline $\mathrm{N}$ & 902 & 360 & 123 & 251 & 168 & \\
\hline \multicolumn{7}{|c|}{ Full-text reading, n (\%) } \\
\hline None & $15(1.7)$ & $6(1.7)$ & $2(1.6)$ & $5(2.0)$ & $2(1.2)$ & 0.462 \\
\hline All & $42(4.7)$ & $21(5.8)$ & $2(1.6)$ & $14(5.6)$ & $5(3.0)$ & \\
\hline \multicolumn{7}{|c|}{ The purpose of reading papers } \\
\hline \multicolumn{7}{|c|}{ Improve the research ability, $\mathrm{n}(\%)$} \\
\hline No & $98(10.9)$ & $46(12.8)$ & $10(8.1)$ & $24(9.6)$ & $18(10.7)$ & 0.431 \\
\hline No & $779(86.4)$ & $308(85.6)$ & $107(87.0)$ & $216(86.1)$ & $148(88.1)$ & 0.876 \\
\hline Yes & $123(13.6)$ & $52(14.4)$ & $16(13.0)$ & $35(13.9)$ & $20(11.9)$ & \\
\hline \multicolumn{7}{|c|}{ Papers or fundings, n (\%) } \\
\hline No & 667 (73.9) & $256(71.1)$ & $83(67.5)$ & $186(74.1)$ & $142(84.5)$ & 0.003 \\
\hline Yes & $235(26.1)$ & $104(28.9)$ & $40(32.5)$ & $65(25.9)$ & $26(15.5)$ & \\
\hline \multicolumn{7}{|c|}{ Factors hindering searching and reading } \\
\hline \multicolumn{7}{|c|}{ Limited searching skills, n (\%) } \\
\hline No & 261 (28.9) & $105(29.2)$ & $45(36.6)$ & $78(31.1)$ & $33(19.6)$ & 0.011 \\
\hline \multicolumn{7}{|c|}{ Limited professional knowledge, n (\%) } \\
\hline No & $609(67.5)$ & $250(69.4)$ & $91(74.0)$ & $177(70.5)$ & $91(54.2)$ & 0.001 \\
\hline Yes & $293(32.5)$ & $110(30.6)$ & $32(26.0)$ & $74(29.5)$ & $77(45.8)$ & \\
\hline \multicolumn{7}{|c|}{ Limited medical research knowledge, n (\%) } \\
\hline No & $435(48.2)$ & $188(52.2)$ & $66(53.7)$ & $112(44.6)$ & $69(41.1)$ & 0.037 \\
\hline Yes & $467(51.8)$ & $172(47.8)$ & $57(46.3)$ & $139(55.4)$ & $99(58.9)$ & \\
\hline \multicolumn{7}{|c|}{ Other reasons, n (\%) } \\
\hline No & $898(99.6)$ & 359 (99.7) & $122(99.2)$ & $249(99.2)$ & $168(100.0)$ & 0.560 \\
\hline Yes & $4(0.4)$ & $1(0.3)$ & $1(0.8)$ & $2(0.8)$ & & \\
\hline
\end{tabular}




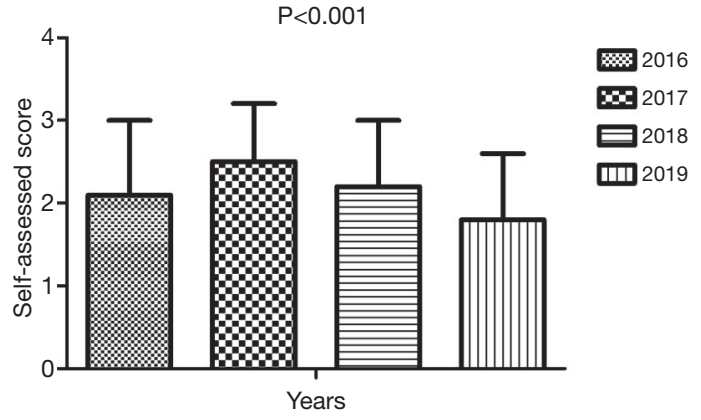

Figure 3 Self-assessed score for literature searching and reading skills ( 1 is the lowest, and 5 is the highest). research process. However, researchers should keep up to date with the progress in their field of study. The latest information can help to inform the direction and design of their research, or support their argument (12); without it, researchers risk missing out on important pieces of data and knowledge. In practice, discovering that similar results have already been published is the worst case scenario for any scholar upon submitting a paper (13).

Further, we analyzed the literature reading habits and utilization of Chinese PGSs. We found that most PGSs only read full texts of selected articles, which is reasonable.

Table 4 Use of reference management software and the needed literature skills in Chinese medical postgraduate students

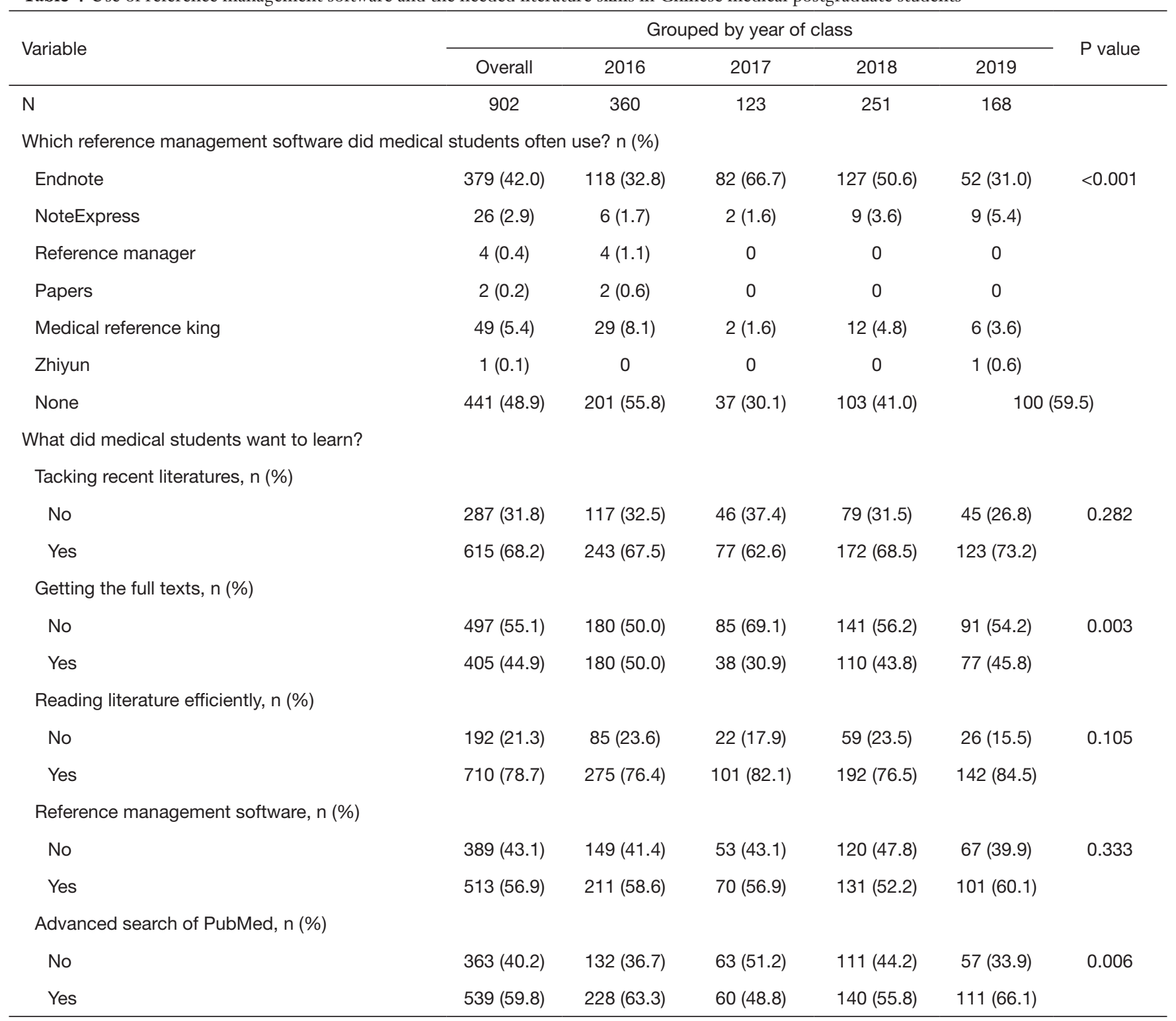


In fact, we found that many PGSs in our study read the full text of fewer than 1 articles per week. Considering these findings, we believe that our PGSs did not read enough medical articles in terms of both depth and amount. We also found that many PGSs did not use tools to manage their references. When a large number of references are needed to write a paper, failure to use a reference management tool can reduce efficiency and often leads to sequential errors or the repetition of references. For the PSGs who used tools, Endnote was the main choice. In terms of citations from references, 274 PGSs would copy the original sentence or statement into their own articles while the majority [511] of PGSs would paraphrase.

This survey also has some limitations. First, there were $22.6 \%$ non-respondents, these PGSs may be poor compliance. Second, graduate students' majors may be an important influence factor that was not discussed in this survey.

In summary, this survey showed that the literature search performance of PGSs was not adequate. Generally, the PGSs in our study did not regard literature searching with enough importance, while some did not perform actively in literature searching. Some PGSs were not good at handling references. All of these factors make it difficult for PGSs to excel in their research work (14). In the future, to ensure PGSs have the basic skills to carry out medical research, we should continue to improve our literature investigation training program, make it easier for PGSs to perform literature searching, and set up strict standards for testing their skills and knowledge of literature searching.

\section{Acknowledgments}

Funding: None.

\section{Footnote}

Reporting Checklist: The authors have completed the SURGE reporting checklist. Available at http://dx.doi. org/10.21037/atm-20-6932

Data Sharing Statement: Available at http://dx.doi. org/10.21037/atm-20-6932

Conflicts of Interest: All authors have completed the ICMJE uniform disclosure form (available at http://dx.doi. org/10.21037/atm-20-6932). The authors have no conflicts of interest to declare.
Ethical Statement: The authors are accountable for all aspects of the work in ensuring that questions related to the accuracy or integrity of any part of the work are appropriately investigated and resolved. This survey was about student habits not related to human health and ethical approval was not required. The study was conducted in accordance with the Declaration of Helsinki (as revised in 2013).

Open Access Statement: This is an Open Access article distributed in accordance with the Creative Commons Attribution-NonCommercial-NoDerivs 4.0 International License (CC BY-NC-ND 4.0), which permits the noncommercial replication and distribution of the article with the strict proviso that no changes or edits are made and the original work is properly cited (including links to both the formal publication through the relevant DOI and the license). See: https://creativecommons.org/licenses/by-nc-nd/4.0/.

\section{References}

1. Siva S. Optimal strategies for literature search. Indian J Urol 2009;25:246-50.

2. França TFA, Monserrat JM. To Read More Papers, or to Read Papers Better? A Crucial Point for the Reproducibility Crisis. Bioessays 2019;41:e1800206.

3. de Meis L, Leta J. Modern science and the explosion of new knowledge. Biophys Chem 1997;68:243-53.

4. Dykes MH. Beating the knowledge and technology explosion. JAMA 1981;246:1924-5.

5. Hesse BW. Role of the Internet in Solving the Last Mile Problem in Medicine. J Med Internet Res 2019;21:e16385.

6. Yuan J, Ni J, Zhu Y, et al. Methods of Critical Reading in Clinical Teaching: Teaching Design and Practice. Medical Journal of Peking Union Medical College Hospital 2019;10:189-92.

7. Littlewood A, Kloukos D. Searching the literature for studies for a systematic review. Part 2: Resources for searching the medical literature. Am J Orthod Dentofacial Orthop 2019;155:445-7.

8. Elston DM. Getting the most out of online literature searches-tips for advanced searches. J Am Acad Dermatol 2019;81:905.

9. Volpato ES, Betini M, El Dib R. Testing search strategies for systematic reviews in the Medline literature database through PubMed. J Eval Clin Pract 2014;20:117-20.

10. Polonioli A. In search of better science: on the 
epistemic costs of systematic reviews and the need for a pluralistic stance to literature search. Scientometrics 2020;122:1267-74.

11. Finfgeld-Connett D, Johnson ED. Literature search strategies for conducting knowledge-building and theorygenerating qualitative systematic reviews. J Adv Nurs 2013;69:194-204.

12. Kurup V, Hersey D. Finding information by "design": search strategies for cardiothoracic and vascular anesthesia literature. J Cardiothorac Vasc Anesth 2010;24:845-58.

13. Donato H, Marinho RT. How to do an effective literature search? The use of Push and Pull strategies. Acta Med Port 2013;26:471-5.

14. Bramer W, Bain P. Updating search strategies for systematic reviews using EndNote. J Med Libr Assoc 2017;105:285-9.

(English Language Editor: J. Reynolds)

Cite this article as: Mao Z, Wu T, Zhang J, Feng D, Chen J, Liu C, Qi S, Li Q, Kang H, Zhou F. Performance of Chinese medical postgraduate students in literature searching: a twocenter survey and analysis. Ann Transl Med 2020;8(21):1453. doi: 10.21037/atm-20-6932 